Journal of Early Intervention, 1997

Vol. 21, No. 1, 73-83

Copyright 1997 by the Council for Exceptional Children

\title{
Parent-to-Parent Programs: A Resource for Parents and Professionals
}

\section{BETSY SANTELLI, ANN TURNBULL, JANET MARQUIS, \& ESTHER LERNER University of Kansas}

Parent to Parent programs offer parents of children who have special needs the opportunity to receive emotional and informational support from another parent who is experiencing a similar set of circumstances. By matching a trained veteran parent of a child with a disability in a 1 -to-1 relationship with a parent who is newly referred to the program, Parent to Parent programs facilitate connections filled with information and perspectives that are unique to parents. This article introduces Parent to Parent support by (a) featuring the matched experience of two parents, (b) describing the results of a national survey of local Parent to Parent programs, (c) presenting guidelines for starting Parent to Parent program, and $(d)$ suggesting resources that are available nationally to those interested in Parent to Parent support.

It's nice here at the table in the kitchen in the morning,

Sitting with our coffee and talking 'bout our kids

Did you ever dream of wheelchairs when you thought of having children

I know most parents worry, and I guess I sorta $\operatorname{did} \ldots$

“Connections” by Tom Hunter

\section{A Parent to Parent Match-Connie's and Laura's Story-Making the Connection}

Laura and Connie sit at the kitchen table, talking and laughing as good friends do when they share time together. They speak about new movies they've seen, work projects, family adventures, and the ups and downs of everyday life. Laura agrees to take care of Connie's daughter Katy while Connie goes to some garage sales, and Connie brings the jeans she has altered for Laura's daughter. They plan activities for their two families, and there will be many in the weeks and months to come.

Laura's and Connie's friendship began as a Parent to Parent match on behalf of their daughters Anna and Katy. Anna, 5, has cerebral palsy and is visually impaired; Katy, 4, has Moebius syndrome, a rare genetic disorder characterized by facial paralysis and visual impairments and one that often affects gross and fine motor skills as well. Both girls were born prematurely and now use walkers. Without a Parent to Parent program in their community, Laura and Connie most likely would not have found each other. Their Parent to Parent match has made a world of difference in the lives of these two families.

\section{What is Parent to Parent Support?}

Parent to Parent programs help parents who have children with special needs find each other and to become reliable allies for each other. When parents who have an infant with a disability are asked who they would like to talk to for support, they most often mention another parent who shares their disability experiences (Boukydis, 1984). Yet parents of children with special needs are often isolated from the mainstreams of family and community life, so finding another parent with a similar set of circumstances is difficult (Dunst, Trivette, \& Cross, 1986; Kazak \& Marvin, 1984). 
Parent to Parent programs provide an opportunity for parents who have children with special needs to connect with and support each other. This opportunity is created when the Parent to Parent program carefully matches a trained, experienced veteran parent in a one-to-one relationship with a parent newly referred to the program. Because the two parents share so many common disability and family experiences, an immediacy of understanding is typically present in the match. This makes the emotional and informational support from the veteran parent all the more meaningful. For some parents, the more intimate, individualized support that is a natural part of a Parent to Parent match best meets their emotional and informational needs.

Parent to Parent programs have been providing the one-to-one matched experience to parents for 25 years. The first Parent to Parent program, Pilot Parents, was launched in 1971 in Omaha, NE, by a parent of a young child with Down syndrome (Iscoe \& Bordelon, 1985). Collaborating with two professionals, she developed a model for (a) handling referrals and making matches; (b) recruiting, screening, and training veteran parents; and (c) providing follow-up support to each match. Soon the Pilot Parents program in Omaha was providing training and technical assistance to other parents and professionals who wished to replicate the Pilot Parents model in their home communities. In some states, a statewide Parent to Parent program emerged to support the efforts of developing local programs in the state (Arizona, Florida, Georgia, New Hampshire, New Mexico, North Carolina, South Carolina, Virginia, Vermont, and Washington are some of the states that launched statewide programs in the 1980s. Today, over 500 active local and 25 statewide Parent to Parent programs provide the one-to-one matched opportunity to over 35,000 parents nationally (Santelli, Turnbull, Lerner, \& Marquis, 1993).

\section{A Parent to Parent Match- Connie's and Laura's Story- Informational Support}

Laura has been a veteran parent for several years as a part of the statewide Parent to Parent program in Kansas coordinated by Families Together, a Parent Training and Information Center. One of her early matches was with Connie, who with her family had just relocated to Kansas.
Because Laura and Connie both have daughters who have similar disabilities and who are about the same age, they share many common joys and challenges. Because Laura has had a bit more experience than Connie at parenting a child with a disability and Laura has had some special training in how to serve as an effective veteran parent, she is able to offer informational support to Connie in a very comfortable way.

Laura and Connie both have girls who because of their disabilities use walkers. Anna has been using a walker for a number of years, while Katy is just now getting her walker. Laura shares lots of creative tips about life with walkers: the importance of trying several different models of walkers before purchasing one; using brightly colored bicycle handles and holiday lights to make the walker more appealing to not only Anna and Katy, but also their peers; and hanging a small canvas bag on the walker to allow the girls to carry supplies at school. These are tips that only a parent who has been there can know. These are all examples of informational support that Laura as a veteran parent offers to Connie.

\section{A Parent to Parent Match- Connie's and Laura's Story- Emotional Support}

When Katy was born she was immediately transferred to the neonatal intensive care unit. Connie was filled with many powerful emotions-fear, confusion, sorrow, guilt, anger-as she sat by the isolette, barely able to see her daughter through all of the technological equipment that kept her alive. Her husband and parents were just as apprehensive about the future and needed the same kind of emotional support for which Connie yearned. Connie knew that she would find it helpful to talk with another parent who had been through a similar experience and she knew such parents were out there, but she didn't know how to find them. Eventually the Parent to Parent program in Kansas helped Connie make the important connection with another 
parent. Because Laura shared the neonatal intensive care unit experience, and because Anna has disabilities similar to Katy's, Laura really understands the many powerful emotions that accompany life with disability. Laura and Connie share a common bond that facilitates intimate emotional sharing. The emotional connection Connie has with Laura helps Connie to acknowledge her own feelings and to begin to plan for the future.

Parent to Parent has been my lifeline. When I first heard the diagnosis, I was devastated. Well-meaning doctors and nurses, as well as friends and families simply did not understand. It was only when I finally connected with another parent through the Parent to Parent program that I could begin to hope for a future for us all. My veteran parent was gently there for me whenever I needed her.

Laura and Connie's match has extended to other members of their families as well. Anna and Katy have become fast friends, and through the outings and activities the two families have shared, Anna's and Katy's dads and older siblings are benefiting from the mutual support of others who have been there.

A Parent to Parent, Parent to Parent Match-Connie's and Laura's Story-Reciprocity

A Parent to Parent match is often reciprocal, especially after some of the more immediate emotional and informational needs of the referred parent have been met. Laura and Connie both acknowledge their importance to each other as reliable allies and as friends. Laura says,

Even though my daughter Anna is older than Katy, and so I have had a few more life experiences with disability issues than Connie, Connie was very much my veteran parent when I needed to purchase a computer for Anna. Katy began using her computer several months before Anna did, and boy, was Connie a valuable resource when it came to finding the funding our family needed to buy Anna her computer.
Connie had already done all of the research, and she was only too happy to share it all with me. What goes 'round comes 'round, and our match has been a wonderful exchange for us both!

\section{Parent to Parent-A Validated National Resource for Parents}

Professionals or parents can provide parent support, in either a group or individual setting. Many parents find that a support group opportunity with several parents coming together at regularly scheduled times for mutual support meets their needs. Professionals or parents facilitate these support groups. For some families, the one-to-one support of a professional (e.g. counselor, social worker, religious leader) best meets their needs. As a uniquely meaningful and innovative approach to parent support, Parent to Parent support rounds out the continuum of support options for parents by providing one-to-one support delivered by parents for parents.

Parent to Parent programs have always been grassroots efforts, generally beginning as small community-based programs energized and directed by the parents who believe in the importance of oneto-one, Parent to Parent support. Because Parent to Parent programs are sometimes not highly visible outside of their home communities, for many years the number and location of Parent to Parent programs was unknown. Parents who were interested in finding out more about Parent to Parent support as a national resource for families asked the Beach Center on Families and Disability at The University of Kansas to conduct a national survey of Parent to Parent programs. The purpose of the survey was to collect descriptive information about the location, administrative structure, and program components of Parent to Parent programs as well as to learn from the parents themselves about their experiences.

Consistent with the procedures of participatory action research, a national advisory board of leaders in Parent to Parent support consulted with the Beach Center researchers to design the survey and build a mailing list of local and statewide Parent to Parent programs. Three mail survey protocols were developed in accordance with many of the mail survey guidelines suggested by Dillman (1978): (a) a survey for program administrators, (b) a survey for referred parents, and (c) a survey for veteran parents. 
Each survey collected both quantitative and qualitative data about the demographics of the program and the participating families, program administration and structural organization, specific program components and activities, and perceptions about the effectiveness of program activities in meeting family needs. The surveys were reviewed by members of the national advisory board and then field-tested with program directors and parents from eight different Parent to Parent programs.

Project staff initiated a variety of public awareness activities to locate Parent to Parent programs nationally, distributing flyers at conferences, submitting articles about the project to 250 family newsletters, working from national advisory board member mailing lists. A project mailing list was developed and approximately 7000 programs/agencies providing services to families who have a family member with a disability received an invitation by mail to participate in the national survey. Those responding programs that were implementing the Parent to Parent model by matching a veteran parent (an experienced trained parent who has volunteered to give support to another parent) received the survey for program administrators. The second phase of the survey occurred 18 months later when program directors of Parent to Parent programs that had completed the program survey received instructions for randomly selecting $30 \%$ of their referred and veteran parents to receive the survey. Each program director needed only to attach the appropriate address labels for the envelopes and forward the packets on to the parents. Over 375 local Parent to Parent program administrators and 600 referred and veteran parents, representing 115 different Parent to Parent programs from 43 of the 50 states, participated in the survey between 1989 and 1993 .

Quantitative data from the surveys were analyzed and descriptive statistics (i.e., means, frequencies, cross tabulations, standard deviations) were calculated. Qualitative data were transcribed and sorted by question number and type of respondent. Data from the survey indicate the following:

- Most Parent to Parent programs are parentdirected, with $78 \%$ of the directors of Parent to Parent programs being parents themselves of a family member with a disability.

- $\quad$ The vast majority of Parent to Parent programs are cross-disability, serving families who have children with a wide variety of disabilities and chronic illnesses. Only 2\% of the responding Parent to Parent programs reported serving only a single disability.

- $\quad$ Parent to Parent programs provide support to parents who have a son or daughter with special needs of any age. Of the families participating in Parent to Parent as referred parents, $85 \%$ have a child with special needs who is younger than 12, although an increasing number of veteran programs are now matching families with adolescents and young adults.

- Referrals to Parent to Parent programs come from a variety of sources, with most referrals (88\%) coming from members of the medical profession.

- Most Parent to Parent programs (76\%) provide training to veteran parents before they are matched, and $44 \%$ of the veteran parents reported receiving at least 10 hours of training. Veteran parent training covers a wide range of topics, with over $85 \%$ of the veteran parents reporting that they were provided training in listening and communication skills, information about the adjustment process, and an orientation to Parent to Parent program goals, activities, and philosophy.

- Matches are made very carefully and take into consideration a wide variety of factors. Most matches (over 90\%) are made based upon similar disability and family issues.

- Most (over 60\%) referred parents mention the emotional support of having someone who shares their experiences to listen and understand, and receiving information about disability and day-to-day living issues, as the most important parts of their match.

- Although the primary mission of Parent to Parent programs is to provide support to referred parents, veteran parents benefit from the matched experience as well. At least $84 \%$ of the veteran parents who responded to the survey indicated that they received personal support from the program coordinator or opportunities for support group activities for themselves. When asked why they chose to participate as veteran parents, as might be expected a vast majority $(90 \%)$ indicated that they wished to provide support to another parent. But a similar majority $(84 \%)$ reported 
that they were serving as a veteran parent so they could give back to the Parent to Parent program or grow personally, perhaps reflecting their sense of gratitude and appreciation for what their involvement has meant to them.

- $\quad$ Statewide Parent to Parent programs exist in 25 states, and these programs provide training and technical assistance to local programs. In some states, the statewide program has a computerized database that allows them to make a statewide match when a local match cannot be found (Santelli et al., 1993).

Comments written on the surveys from parents participating in one-to-one matches strongly emphasized the importance of Parent to Parent support. A referred parent wrote,

Our support parent has been terrific from the very first moment she walked into the hospital room. My husband and I were so numb with shock that we didn't know which way to turn, and we needed someone to give us some direction. She cried with us-real tears that only another parent can generate-and then helped us to see our way through some major decisions. When our daughter was diagnosed with a major heart defect that would require open-heart surgery, she gave blood for her surgery. She took us out to eat while our daughter was in intensive care, and later she even came to her first birthday party. She has become one of our dearest, closest friends.

Her veteran parent explains her commitment to Parent to Parent support:

When my son was born, there was no local Parent to Parent program, and I felt very alone and scared. There was simply no one who could possibly understand what I was feeling. For that first year until I finally connected with another parent in our new Parent to Parent program, I kept all of my feelings tightly inside. Meeting another parent whose child also had Down syndrome helped me to reconnect with life. So when I was trained as a veteran parent and first walked into that hospital room to meet my referred parent, so many memories filled my heart-both painful ones and joyful ones. I so wanted to help her stay connected with life.
A national study to determine the effectiveness of Parent to Parent support for the referred parents, directed by Dr. George Singer and implemented by a consortium team of parents and researchers in five states, was completed in July 1996 (Singer et al., 1996). A parent-researcher team in each of the five states recruited a total of over 350 parents who have a child with special needs and who had never been in a Parent to Parent match. These referred parents completed a set of questionnaires before, during, and after their matches that yielded quantitative data about the impact of the Parent to Parent match on their level of acceptance, empowerment, coping, social support, and sense of having a reliable ally. Telephone interviews were conducted with a random sample of referred parents to collect qualitative data about heir matched experience and its impact. The specific findings are reported in a forthcoming article. Briefly, the data indicate the following:

- Parent to Parent support increases parents' sense of being able to cope.

- Parent to Parent support increases parents' acceptance of their situation.

- Parent to Parent helps parents make progress on the need they present when they first contact a Parent to Parent program.

- Over $80 \%$ of parents find Parent to Parent support to be helpful.

- There is a strong relationship between the number of contacts a parent has with a veteran parent and how helpful the parent finds Parent to Parent support to be.

Additional research is needed and is being planned to determine the impact of the Parent to Parent experience for veteran parents.

\section{Parent to Parent-A National Resource for Early Intervention Professionals}

Early intervention professionals can both benefit from and contribute to the development of Parent to Parent programs. As natural allies for early intervention professionals who may want to be more responsive to family preferences but find thems elves hindered by their own realities of time and their lack of personal experiences, Parent to Parent programs provide the important support that parents most request. A service provider speaks about the value of Parent to Parent for professionals:

When the Parent to Parent program was established, we knew that the program 
would be of assistance to families, but we didn't realize until later that it would also be of great assistance to the staff. As professionals, we often feel inadequate, because we cannot truly understand what families are going through since we haven't actually experienced what they have. Our staff became aware that this program could fulfill a need for families that they as professionals could not. In this way, the program supports the role of the professional as well as supporting the family.

Parent to Parent programs rely on referrals from service providers. Early intervention service providers can contribute to the success of Parent to Parent programs by telling parents about the support Parent to Parent programs offer and by helping parents get connected to the nearest local program.

\section{Finding a Parent to Parent Program}

Early intervention professionals who are looking for a Parent to Parent program on behalf of a family can contact the statewide Parent to Parent programs in 25 states (a list of these programs appears a the end of this article). Statewide programs maintain lists of the local programs in their states and can put parents in touch with the program closest to them. Information about local Parent to Parent programs in states that do not have a statewide program can be obtained by calling the Beach Center (number at the end of this article).

\section{Developing a Parent to Parent Program}

When a community does not have a local Parent to Parent program, service providers who know about Parent to Parent support can discuss the idea with parents and then may be able to offer funding or inkind supports to parents as they develop their program. Steps to starting a Parent to parent program include the following:

- Deciding about sponsorship. A Parent to Parent program may be established as an entirely volunteer organization, or it may be sponsored by a service provider agency, disability organization, or existing parent group. Whether to seek sponsorship is a crucial early decision, and the advantages and disadvantages of sponsorship need to be considered carefully.

- Seeking funding. Parent to Parent programs can be operated on a totally volunteer basis with little or no funding, but even a small operating budget will allow the program to expand more rapidly. A sponsored Parent to Parent program may receive direct funding support from the sponsoring agency. Requesting donations, writing for local and state grants, and staging community-based fundraising efforts (e.g. bake sales, silent auctions) are fundraising strategies often used by developing programs.

- Learning more about Parent to Parent support. Many excellent information and training materials on Parent to Parent program development have been produced by existing Parent to Parent programs. Contact the Beach Center for further information.

- Informing local service providers. Telling local service providers who will serve as sources of parent referrals about the program is a critical element in its success. Programs use person-to-person contacts, printed materials, and the media to help get the word out.

- Recruiting and training veteran parents. Work with community agencies to invite experienced parents to consider serving as veteran parents. Screen prospective veteran parents in terms of their adjustment to their family situation, communication skills, maturity, empathy, and time availability. Develop and facilitate at lest 4 hours of training for veteran parents, covering the following content areas:

- Orientation to the Parent to Parent program

- $\quad$ Positive philosophy about persons with disabilities

- Self-awareness activities

- Information about community resources and the referral process

- Communication and listening skills

- Adjustment to the disability experience.

Contact the Beach Center to learn more about training manuals available from many existing Parent to Parent programs.

- Establishing the referral and matching system.

- $\quad$ Select a local referral telephone number to publish and distribute to all potential referral sources. Ideally, the person responding to incoming calls should be a 
parent of a child with special needs, but an answering machine will ensure that all calls are received.

- Make matches on as many similar factors as possible, because the more the parents have in common, the easier it is for them to empathize with each other.

- Once an appropriate match has been determined, contact the veteran parent to be sure that he or she is ready to support another parent in a match. Once the match is made, the veteran parent makes every effort to contact the referred parent within 24-48 hours of the time the referral came into the program.

- As the match evolves, offer veteran parents follow-up support either by telephone or in person.

- Establish an orderly, easily accessible system for documenting matches.

\section{National Resources for Parent to Parent}

- Although there is no national Parent to Parent organization, Parent to Parent programs and families get together at the International Parent to Parent Conference every other year. A different statewide program hosts this conference each time, bringing together nearly 1500 parents and professionals to share information and resources. The next conference is scheduled for the spring of 1998.

- When a parent who has a child with a very rare disability cannot find a local or statewide match, the National Parent to Parent Support and Information System (NPPSIS) makes national and even international matches using its computerized database. To contact NPPSIS, call (800) 651-1151.

- $\quad$ Parent to Parent programs are increasing their visibility and accessibility through the Internet. A listing of some website addresses appears at the end of this article.

- The Beach Center on Families and Disability has produced a number of products for those interested in Parent to Parent support.

1. The National Resource Directory of Parent to Parent Programs provides information about the location and characteristics of several hundred Parent to Parent programs.
2. A comprehensive summary of the results of the national survey of Parent to Parent programs is presented in The Parent to Parent National Survey Results.

3. The Parent to Parent Annotated Bibliography provides a summary of field-related literature for Parent to Parent support along with suggested uses for each article, book, or chapter.

4. For an introduction to Parent to Parent support, the Parent to Parent Information Packet summarizes information about the Parent to Parent model and presents some guidelines for starting a program.

5. Parent to Parent : Answers to Your Questions provides detailed answers, based upon the survey's descriptive statistics, to typical questions about Parent to Parent support.

6. Parent to Parent: A National Resource is a 30minute videotape that introduces Parent to Parent support through discussions with national leaders in Parent to Parent support and provides examples and scenes from parents participating in a match.

7. Parent to Parent Program Evaluation Manual, developed by the members of the consortium team of parents and researchers who conducted the National Study to Determine the Effectiveness of Parent to Parent Support, provides concrete steps, sample instruments, and general procedures to follow when conducting program evaluation for Parent to Parent programs.

8. Pierson Award Directory describes the best practices of all of the Parent to Parent programs that were nominated for the Pierson Award-an award honoring and celebrating excellence in the supports and services provided by Parent to Parent programs.

9. Connections, a collection of songs that are both comforting and energizing about families and disability.

For additional information about these products and other resources in Parent to Parent support, please contact:

The Beach Center on Families and Disability

Parent to Parent Projects

3111 Haworth Hall

University of Kansas

Lawrence, KS 66045 
(785) $864-7600$

FAX: (785) 864-7605

WWW address: www.beachcenter.org

Email: Beach@ku.edu

\section{REFERENCES}

Boukydis, C.F. (1984, October). The importance of parenting networks. Paper presented at the Parent Care Conference, Salt Lake City, UT.

Dillman, D.A. (1978). Mail and telephone surveys: The total design method. New York: John Wiley \& Sons.

Dunst, C.J., Trivette, C.M., \& Cross, A. (1986). Roles and support networks of mothers of handicapped children. In R. Fewell \& P. Vadasy (Eds.), Families of handicapped children: Needs and supports across the lifespan (pp. 167-192). Austin, TX: PRO-ED.

Iscoe, L., \& Bordelon, K. (1985). Pilot Parents: Peer support for parents of handicapped children. Children's Health Care, 14, 103-109.

Kazak, A.E., \& Marvin, R.S. (1984). Differences, difficulties, and adaptations: Stress and social networks in families with a handicapped child. Family Relations, 33, 67-77.

Santelli, B., Turnbull, A., Lerner, E., \& Marquis, J. (1993). Parent to Parent programs: A unique form of mutual support for families of persons with disabilities. In G. Singer \& L. Powers (Eds.), Families, disability, and empowerment: Active coping skills and strategies for family interventions (pp. 2758). Baltimore, MD: Paul H. Brookes Publishing Co.

Singer, G.H.S., Powers, L.E., Marquis, J.G., Blanchard, L., DiVenere, N., \& Sharp, M. (1996). An evaluation of parent to parent self-help programs in five states: Evidence for efficacy. Manuscript submitted for publication.

Betsy Santelli, Beach Center on Families and Disability; Ann Turnbull, Beach Center on Families and Disability; Janet Marquis, Schiefelbusch Institute for Life Span Studies; Esther Lerner Schiefelbusch Institute for Lifespan Studies.
Address correspondence to Betsy Santelli, Beach Center on Families and Disability, 3111 Haworth Hall, University of Kansas, Lawrence, Kansas 66045. Email: betsy@dole.lsi.ukans.edu.

\section{SOME PARENT TO PARENT INTERNET ADDRESSES}

\section{Parent to Parent Programs}

Parents Helping Parents, Santa Clara, CA

http://www.php.com

Family Resource Network, Stockton, CA http://stocktonet.com/groups/frn

Family Network on Disabilities of Florida, Clearwater, FL

http://www.gate.net/ fnd/

Parent to Parent of the Capital Area, Tallahassee, FL http://www.freenet.tlh.fl.us/Parent to Parent

Parent to Parent of Georgia

http://www.parenttoparentofga.org/home.htm

Indiana Parent Information Network, Indianapolis, IN http://www.ai.org/ipin

Nevada Parent Network, Reno, NV

http://www.scs.unr.edu/repc/npn.html

Family Support Network of North Carolina, Chapel Hill, NC

http://www.med.unc.edu/wrkunits/ldean/commendu/f amilysu/welcome.htm

Family Connection of South Carolina, Columbia, SC http://www.colum.mindspring.com/ famconn

Parent to Parent of Washington, Seattle, WA http://www.prostar.com/ the.arc/ptp.htm

\section{Other National Resources}

Beach Center on Families and Disability, Lawrence, KS http://www.beachcenter.org/

Center for Children with Chronic Illness and Disabilities, Minneapolis, MN http://www.peds.umn.edu/Centers/c3id/directory.html 
Exceptional Parent Magazine, Brookline, MA http://www.familyeducation.com

The Family Village, Madison, WI http://www.familyvillage.wisc.edu

MUMS National Parent to Parent Program, Green Bay, WI

http://www.waisman.wisc.edu/ rowley/mums/home.ht $\underline{m l x}$
National Information Center for Children and Youth with Disabilities (NPPSIS)

http://nppsis.org

Parent Advocacy Coalition for Educational Rights (PACER)/Technical Assistance Alliance for Parent Rights

http://www.taalliance.org

Sibling Support Project, Seattle, WA

http://www.chmc.org/departmt/sibsupp

\section{STATEWIDE PARENT TO PARENT PROGRAMS}

\begin{abstract}
Arizona
Pilot Parent Partnerships

4750 Black Canyon Highway

Suite 101

Phoenix, AZ 85017-3621

(602) 242-4366
\end{abstract}

Arkansas
Parent to Parent
2000 Main
Little Rock, AR 72206
(501) 375-7770
FAX: (501) 372-4558
California
Parents Helping Parents
3041 Olcott Street
Santa Clara, CA 95054-3222
(408) 727-5775
FAX: (408) 727-0182
Michigan
Family Support Network of
Michigan
1200 6 ${ }^{\text {th }}$ Street, $9^{\text {th }}$ Floor
North Tower
Detroit, MI 48226
(313) 256-2186
FAX: (313) 256-1844
Nevada
Nevada Parent Network
University Affiliated Program
In Research and Educational
Planning Center
College of Education/278
Reno, NV 89557-0082
(702) 784-4921

\author{
Connecticut \\ Parent to Parent Network of CT \\ The Family Center \\ 181 East Cedar Street \\ Newington, CT 06111 \\ (806) 545-9023
}

\section{Florida}

Family Network on Disabilities of Florida

2735 Whitney Road

Clearwater, FL 34520

(813) 523-1130

FAX: (813) 523-8687

\section{Georgia}

Parent to Parent of Georgia

2900 Woodcock Blvd., Suite 240

Atlanta, GA 30341

(770) $451-5484$

FAX: (770) 458-4091

\section{New York}

Parent to Parent of New York

State

Balltown and Consaul Roads

Schenectady, NY 12304

(800) 305-8817

FAX: (518) 381-4370

\section{North Carolina}

Family Support Network of NC

CB \#7340, Chase Hall

University of North Carolina

Chapel Hill, NC 27699-7340

(919) 966-2916

FAX: (919) 966-2916

\section{Indiana}

Indiana Parent Information

Network

4755 Kingsway Drive, Suite 105

Indianapolis, IN 46205

(317) 257-8683

\section{Kansas}

Families Together, Inc.

501 SW Jackson, Suite 400

Topeka, KS 66603

(913) 233-4777

FAX: (913) 223-4787

\section{Kentucky}

Parent Information Network of Kentucky 1887 Rutherford Avenue Louisville, KY 40205-1856 (502) 452-6923

FAX: (502) 485-0035

\section{Tennessee}

Parents Encouraging Parents $5^{\text {th }}$ Floor, Cordell Hull Building 426 Fifth Avenue, North Nashville, TN 37247-4850 (615) $741-8530$ FAX: (615) 741-1063

\section{Utah}

HOPE-A Parent Network 2290 East 4500 South, Suite 110 Salt Lake City, UT 84117 (801) 272-8907

FAX: (801) 272-8907 
FAX: (702) 784-4997

New Hampshire

Parent to Parent of New Hampshire 117 Mascoma Street, PO Box 622

Lebanon, NH 03766

(603) 448-6311

FAX: (603) 448-1841

\section{New Jersey}

Parent to Parent of New Jersey c/o SPAN

35 Halsey St., $4^{\text {th }}$ Floor

Newark, NJ 07102

(800) $372-6510$ (NJ only)

FAX: (373) 642-8080

New Mexico

Parents Reaching Out

1000A Main Street

Los Lunas, NM 87037

(505) $865-3700$

FAX: (505) 865-3737

\section{Ohio}

The Family Information Network 246 N. High Street, $5^{\text {th }}$ Floor

Columbus, OH 43266-0118

(614) 644-8389

FAX: (614) 644-1759

\section{Pennsylvania}

Parent to Parent of Pennsylvania 150 S. Progress Avenue

Harrisburg, PA 17109

(717) 540-4722

FAX: (717) 540-7603

\section{South Carolina}

Family Connection of South

Carolina

2712 Middleburg Drive

Suite 103-B

Columbia, SC 29204

(803) 252-0914

FAX: (803) 799-8017

\section{Vermont}

Parent to Parent of Vermont

1 Main Street

69 Champlain Mill

Winooski, VT 05404

(802) 655-3507

FAX: (802) 655-3507

Virginia

Parent to Parent-Family and

Children's Services

1518 Willow Lawn Drive

Richmond, VA 23230

(804) 282-4255

FAX: (804) 285-3701

West Virginia

Parent to Parent of

West Virginia

PO Box 3698

(304) 766-1154

\section{Washington}

Parent to Parent Support Program 10550 Lake City Way NE, Suite A

Seattle, WA 98125

(206) 364-4645

FAX: (206) 364-8140

This research was supported by a grant from the National Institute on Disability and Rehabilitation Research to the Beach Center on Disability, Grant \#H133B30070. 